\section{Interchange of the Ammonium and Potassium Ions in Muscle and Yeast}

SINCE the muscle membrane is permeable to the ammonium ion, from the theory of potassium equilibria previously described ${ }^{1,2}$, the following should hold:

$$
a / a_{1}=k / k_{1}=h / h_{1}
$$

where $a, a_{1}, k, k_{1}$ and $h, h_{1}$ are the concentrations of ammonium, potassium and hydrogen ions outside and inside the membrane. On investigation, it appeared that the ammonium ion (or possibly the minute amount of associated free base) has a marked effect on the membrane itself, all ratios being lowered across it (Fenn and Cobb have described such an effect of ammonia on potassium ${ }^{3}$ ).

With the sartorius muscle of the frog immersed. at $2-3^{\circ} \mathrm{C}$. in a Ringer fluid designed to maintain constant volume ${ }^{2}$, and in which $a$ has the low value of $1 \mathrm{mgm}$. NH-N/100 ml., $k$ being $117 \mathrm{mgm} . / 100 \mathrm{ml}$. (30 m.eq./litre), the equilibrium $a / a_{1}$ value of $2 \cdot 1$ is reached quickly, but that for potassium very slowly, since much potassium must come out under these conditions and sodium enter. After forty-eight hours the $k / k_{1}$ value approaches that for $a / a_{1}$ and has fallen from an initial figure of $4 \cdot 0-2 \cdot 3$.

When the external potassium is much raised-to upwards of $300 \mathrm{~m}$.eq./100 ml.-with provision for maintaining constant volume ${ }^{2}$ the $k / k_{1}$ ratio across the membrane is much lowered both theoretically and experimentally, and then small ammonium concentrations have no apparent effect on it. After twenty-four hours in the cold, with external $k$ of 150, 210 and $300 \mathrm{~m}$.eq./litre, the $a / a_{1}$ values are $1 \cdot 51,1 \cdot 33$, and $1 \cdot 28$, the $k / k_{1}$ equilibria even without any ammonium being $1 \cdot 56,1 \cdot 36$ and $1 \cdot 28$. The results are therefore in accord with theoretical expectation and show a specific effect of the ammonium salt on the muscle membrane.

Yeast. The specific membrane effect of the ammonium ion (or associated base) on muscle is not evident with yeast, and ammonium ion can be made to replace the whole of the potassium within the cell, after which it can be taken out and the potassium replaced. (At the same time it may be noted that the simple equilibrium equations applicable to a distensile membrane are not valid for the comparatively rigid membrane of yeast.) A striking peculiarity of the yeast permeability is that the replacement with ammonium goes at a practically negligible rate unless the yeast mixture is bubbled with carbon dioxide (3-10 per cent), bubbling with oxygen at the same $p H$ being almost ineffective. Even with carbon dioxide the entrance is very slow compared with muscle and considering the size of the yeast cell. After fortyeight hours at room temperature all the potassium can be taken out, though much the greater part is lost in twenty-four hours and occasionally practically all of it. The following example may be given :

Sample of pressed bakers' yeast suspended in Ringer solution for a short time and centrifuged.

$K$ content $\quad \ldots \quad \ldots \quad \quad \ldots \quad 450 \mathrm{mgm} . / 100 \mathrm{gm}$.

Bubbled for $24 \mathrm{hr}$. with 3 per cent $\mathrm{CO}_{2}, 97$ per cent $\mathrm{O}_{2}$, in Ringer fluid containing $11.9 \mathrm{~m}$.eq. bicarbonate/litre and varying strengths of

\begin{tabular}{|c|c|c|c|c|}
\hline $\mathrm{NH}_{4} \mathrm{Cl}$ in Ringer fluid & $\rightarrow$ & $N / 5$ & $N / 20$ & $N / 100$ \\
\hline $\mathrm{NH}_{\mathbf{s}}-\mathrm{N}$ in yeast & $\cdots$ & 400 & 174 & 51 \\
\hline $\mathrm{K}$-in yeast (mgm./10 & gm.) & 0 & 192 & 268 \\
\hline
\end{tabular}

Yeast centrifuged and washed in a similar Ringer fluid containing $30 \mathrm{~m} . e q . / \mathrm{KCl}$ per litre and no $\mathrm{NH}_{4} \mathrm{Cl}$; then bubbled in this fluid as before for $24 \mathrm{hr}$.

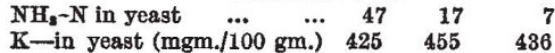

The complete replacement of the potassium with $\mathrm{NH}_{4}$ followed by the subsequent reversal shows that potassium in. yeast is altogether in the ionized condition.

University College, Dublin. Sept. 16.

${ }^{1}$ Conway, E. J., and Boyle, P. J., Nature, 144. 709 (1930). 2 Boyle, P. J., and Conway, E. J., J. Physiol., 100, 1 (1941).

senn, W. O., and Cobb, D. M., J. Gen. Physiol., 17, 629 (1934).

\section{Effect of Sodium and Potassium Ions on Cholinesterase}

Mendel, Mundell, and Strelitz ${ }^{1}$ reported inhibition by potassium ions, and activation by calcium ions, of cholinesterase from horse serum; and they suggested that certain physiologically antagonistic actions of these ions might be explained on this basis. Nachmansohn ${ }^{2}$ stated that sodium and potassium ions in high concentrations activate the cholinesterase from the electric organ of the Torpedo to the same degree, but no experimental data were given. Nachmansohn's communication evoked critical replies from Mendel, Mundell, and Strelitz ${ }^{3}$, and Massart and Dufait ${ }^{4}$. The former authors raised the possibility of differences in the enzyme systems in horse serum and Torpedo, and also suggested that the sodium and potassium salts used by Nachmansohn may have contained sufficient of the activating bivalent metals to give the effect he reported.

In order to throw light on this controversial issue the present study was made, dealing with the effect of the addition of chemically pure sodium chloride and potassium chloride to cholinesterase-acetylcholine chloride systems using dialysed horse and rabbit sera as sources of the enzyme. The usual manometric method employing the Warburg apparatus was used with the substitution of 0.20 per cent $\mathrm{NaHCO}_{3}$ for bicarbonate-Ringer solution. The accompanying figure demonstrates the activating effect of both salts upon the activity of the rabbit enzyme. However, neither of the salts produced a consistent activation

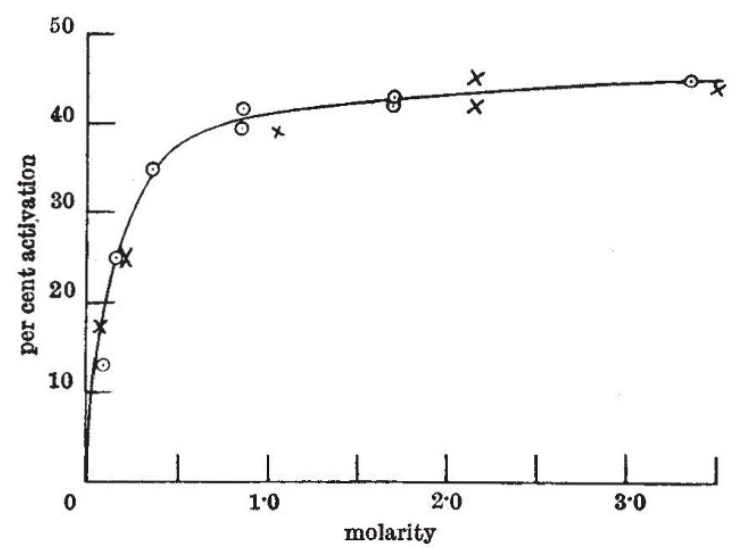

EFHECT OF SODIOM AND POTASSIUM IONS ON CHOLINESTERASE IN RABBIT SERUM.

$\times, \mathrm{NaCl} ; \odot, \mathrm{KCl}$. Hydrolysis measured at $30^{\circ} \mathrm{C}$. in a total volume of 4 c.c. containing $15 \mathrm{mgm}$. acetylcholine chloride and 0.2 c.c. dialysed serum. Reaction period, 120 minutes. Corrections applied for nonenzymatic hydrolysis in presence of the corresponding concentration of the appropriate salt. 